\title{
Healthcare in Serbia in transition period
}

\author{
Zoran Vlahovic • Dragica Radojkovic
}

Received: 11 September 2010 / Accepted: 1 November 2010/Published online: 20 November 2010

(C) European Association for Predictive, Preventive and Personalised Medicine 2010

\begin{abstract}
The main topics of this paper are the socialized healthcare system in former Yugoslavia, the changes in the transition period within the society and the healthcare system. We have separately analyzed the factors of the demographic and socioeconomic situation, the usage of the existing capacities within the system, as well as the comparison of the data related to the healthcare system in Serbia versus the EU countries. The analysis presented has pointed to the usual challenges present in the countries in transition as well as the efforts by the Government and the Ministry of Health of the Republic of Serbia in the way of numerous national and strategic documents, initiatives and projects in order to improve and sustain the healthcare system.
\end{abstract}

Keywords Transitional changes · Healthcare reform . Health policy Prevention programs

\section{Introduction}

The main features of the healthcare system in the social structure that is behind us, have been a very high level of socialized healthcare available free of charge to all age and social groups. Healthcare system still lacks efficiency and

D. Radojkovic is a National Representative of EPMA in Serbia \& Montenegro.

Z. Vlahovic

Clinical Center Dr. Dragisa Misovic,

Belgrade, Serbia

D. Radojkovic $(\square)$

Institute of Molecular Genetics and Genetic Engineering,

University of Belgrade,

Belgrade, Serbia

e-mail: dragica.radojkovic@gmail.com rational approach, and is, thus, ready for a change. In the last decade, healthcare in Serbia has been operated in the environment characteristic for the transition countries with limited financial resources and efforts have been made to create a healthcare system in line with European standards. In this paper, we present and discuss the features that determine the characteristics of the healthcare system at the time when the country is going through major economic difficulties and trying to position itself politically in the region [1].

\section{The reform framework}

In an effort to reform the healthcare system and adapt it to European standards, the Serbian Government, Ministry of Health and the Institute of Public Health issued a number of multi-sector, strategic and planning documents:

The Health Policy of Serbia (2002); Strategy for the healthcare system till 2015 including the Action Plan ( 2003); Health Program for infectious diseases $(2002,2010)$; Strategy for Poverty Reduction (2003); Strategy for integration and improvement of living conditions of Roma population (the Decade of Roma, 2004); the National Action Plan for Children (2004); Strategy for fighting HIV / AIDS (2005 2010); Tobacco Control Strategy of the Republic of Serbia (2005); Health Program for tuberculosis (2005); National Millennium Development Goals in the Republic of Serbia (2006); Youth Health Strategy (2006); The National Strategy on Aging 2006-2015 (2006); National Strategy for Mental Health (2006); National Strategy for fighting drugs and alcohol (2007); Strategy to ensure sufficient amounts of safe and secure food (2007) and Strategy for Public Health (2007) [2, 3].

The main directions of the healthcare system, defined as the most important health policy, are: 
- Health maintenance, improvement and strengthening of the national health potential

- Fair and equal access to healthcare for all citizens, and improvement the protection of vulnerable population groups

- Setting up the healthcare consumers in the center of the healthcare system

- Sustainability of the health system, with selective decentralization and expansion of funding resources

- Improvement of the performance, efficiency and quality of healthcare

- Defining the role of the private sector in providing health services to consumers

- Improving the healthcare human resources database

A particularly important task is to place a patient in the center of the healthcare system, which is summarized in Table 1.

\section{Socioeconomic situation}

Socioeconomic indicators as determinants of health and healthcare, starting the year 2000, reported both positive and variable values.

Although the positive changes in the gross domestic product per capita (GDP) in Serbia (\$3177 in 2004 and in $\$ 6800$ in 2008) were encouraging, their impact was almost diminished when the value of GDP was expressed in terms of purchasing power parity in 2008. The 35 index points from the average for EU countries placed Serbia among the countries with the lowest values in Europe.

According to data provided by National health account, total expenditures for healthcare in Serbia in 2007, amounted to $9.6 \%$ of GDP, which is above the EU average $(8.9 \%)$. On the other hand, if we are looking at the same data from the other point of view, relaying on the absolute amounts observed, the situation is completely different due to the low value of GDP. The structure of expenditures within GDP was the following: $63.8 \%$ representing the share of public expenditure (compulsory health insurance, the budget of administrative units), while the share of private expenditures (participation and direct payment) represented $36.2 \%$ of total healthcare expenditures.

The average salary has increased from $€ 194$ in 2004 to $€ 400$ in 2008. After this period of positive trend, a slowdown in growth has been observed, especially in the public sector.

In the period 2000-2008, the unemployment rate in Serbia has been constantly increasing from 3.3\% in 2000, to $14.7 \%$ in 2008 . This is significantly higher than the average rate of $7.2 \%$ in EU countries, as well as in neighbouring countries $(9.6 \%$ in Croatia; $7.7 \%$ in Slovenia; $6.9 \%$ in Bulgaria) (Figs. 1 and 2).

The socioeconomic indicators in comparison with the European Union countries and especially with the countries in the region represent a serious limitation factor for sustainable financing of healthcare in Serbia [4, 5].

\section{Demographic situation}

After several decades of growth, the population of Serbia has been continuously decreasing starting in 2002 (based on the data of the Statistical office of the Republic of Serbia). In 2002, the number of inhabitants was 7893 125, while in 2008 the number of inhabitants was 7350222 (the index value of 93.1). The same situation was present in Belgrade, capital of Serbia until 2002, and then the tendency of increase was observed (from 1576124 inhabitants in 2002, to 1621996 inhabitants in 2008, the index value of 102.9)

The subjects older than 65 years represent $17.18 \%$ in the total population, which is higher than the average value of $15.1 \%$ in EU countries, while the share of those under age of 14 years $(15.5 \%)$ was lower, compared to the EU
Table 1 Setting a patient in the center of the healthcare system
Provision of social rights, which will be implemented through:

- The right to equal availability and accessibility of healthcare

- Elimination of the discriminatory barriers (economic, geographic, social, psychological), which hinder the implementation of the prior law

Provision of individual consumer rights, which include:

- The right to information

- The right to give consent for medical intervention, and the right to express their views and opinions

- The right to confidentiality of health information that is disclosed in a medical institution

- The right to privacy

- The right to healthcare that fits their needs;

- The right to quality care, which corresponds to the best standards

- The right to safety within the health system

- The right to contact the person in charge ("patient advocate") in every health institution 
Fig. 1 The unemployment rate in Serbia

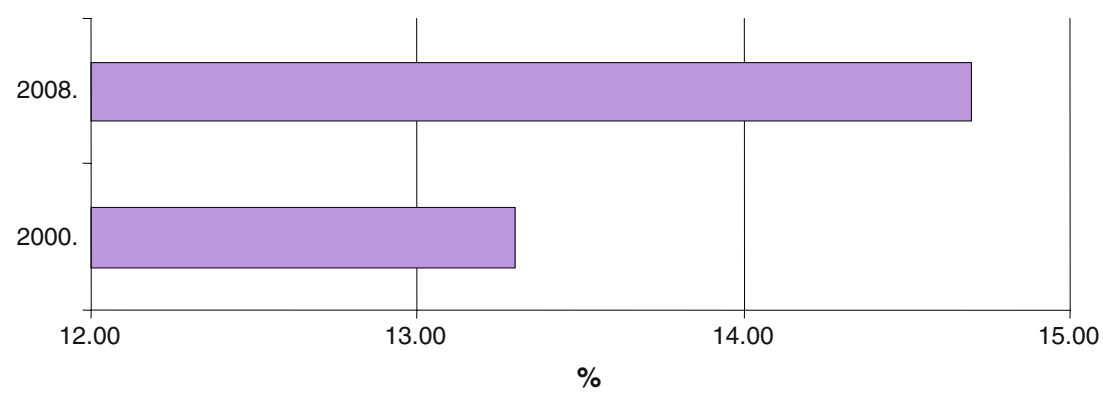

average of $17 \%$. The life expectancy is in a slight increase, with values of 73.65 years in Serbia and 74.46 years in Belgrade in 2008. In 2008, the proportion of women in reproductive age, in the age structure was $23.19 \%$. Both rates showed decrease from 10.5 live births per 1000 inhabitants in 2004, to 9.4 in 2008. During the period 2004-2008, both natural population growth rate, and infant mortality rate were in decline (Fig. 3).

This decline in infant mortality rate is encouraging, as well as the most important indicators of socioeconomic situation represented with 8.1 infant deaths per 1,000 live births in 2004 in comparison to 6.7 per 1,000 live births in 2008. However, when compared with EU countries (4.6 per 1,000 live births), this is still not satisfactory.

The main demographic characteristics of Serbia are the population size reduction and aging population.

\section{Health condition}

Demographic situation in which aging population is dominant, in combination with unfavorable social and economic situation in the last two decades, have had an adverse effect on national health. According to the Development healthcare, "the nation's health potential has run out, and accordingly, in the period of socioeconomic recovery, burdened with the difficulties in a state and social transition, one could not expect a quick improvement of negative health indicators".

Dominant health problem and the leading cause of diseases, disability and premature death are chronic no communicable diseases dominated by ischemic heart disease, cerebrovascular disease, lung cancer, affective disorders (unipolar depression), and diabetes. In the year 2008, chronic non-infectious diseases were the cause of death in more than $85 \%$ cases. The most frequent causes of mortality are heart and blood vessels diseases (55.8\%), followed by malignant diseases $(20 \%)$. Injuries and poisoning contribute to $3.6 \%$ of deaths chronic obstructive disease (COPD) $-3.0 \%$ and complications of diabetes are responsible for $2.6 \%$ of the total number of deaths (Fig. 4).

A specific increase in mortality from malignant tumors and diabetes in the last decade has been observed: standardized mortality rate from malignant diseases in Serbia in 2007 was 203 per 100 000, in comparison with 169 per 100000 in EU countries. A slight decline in mortality from circulatory system diseases has been recorded, and in particular the reduction of $13.6 \%$ of the mortality rate from ischemic heart disease. However, in comparison with the EU countries, death rates from cardiovascular diseases are still high, illustrated by standardized mortality rate of 542 in Serbia compared to 199 in EU countries and mortality rates from ischemic heart disease of 122 in Serbia and 77 in EU countries [6].
Fig. 2 The unemployment rate in Serbia, the European Union and neighbouring countries in 2008

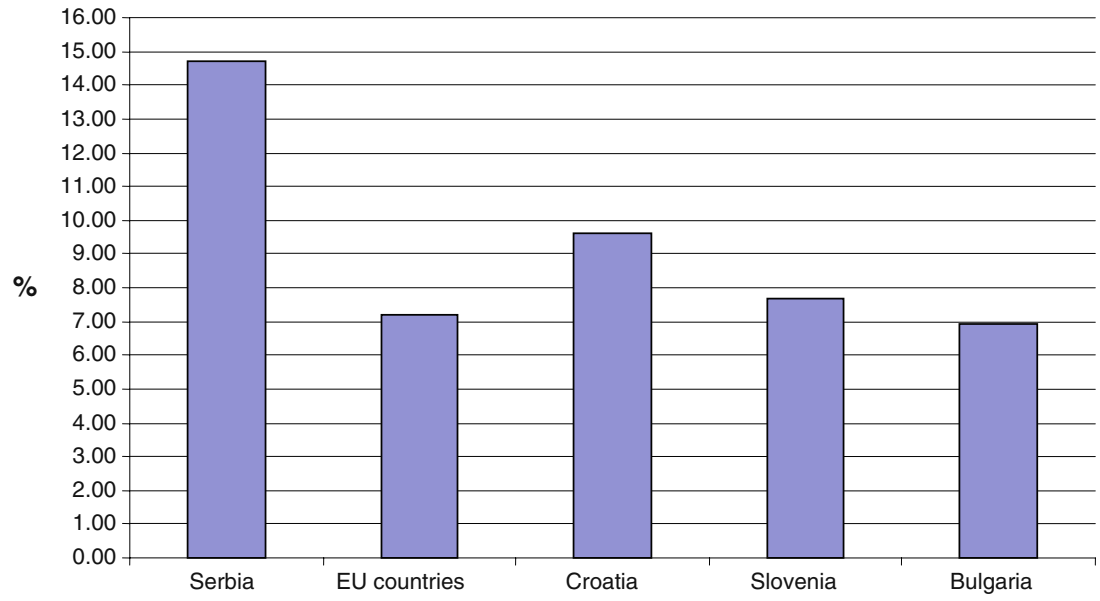


Fig. 3 Birth rates, natural mortality, and infant mortality in Serbia

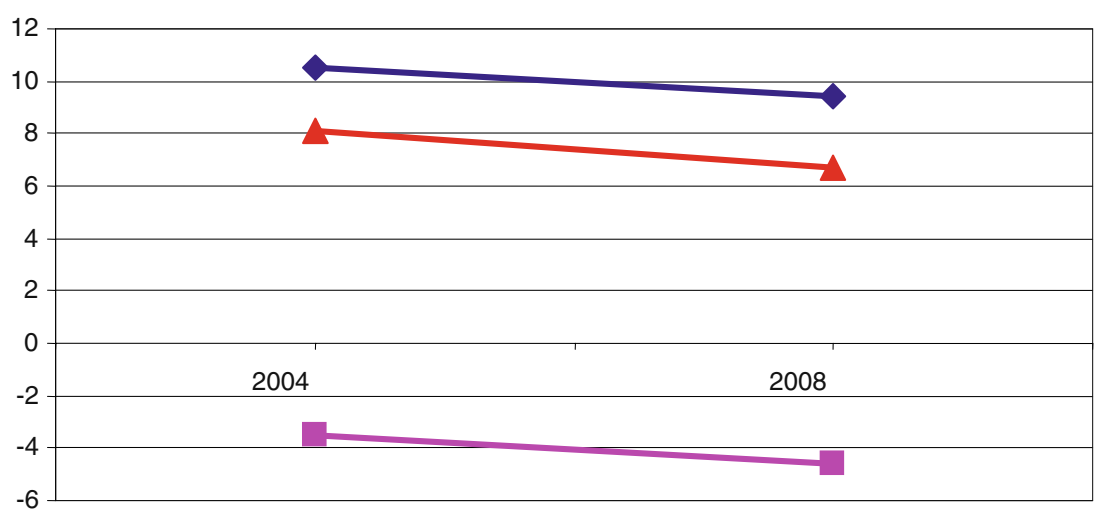

$\sim$ Birth rate $\quad \rightarrow$ Natural population growth rate $\rightarrow-$ Infant mortality rate
Risk factors such as smoking, bad diet, obesity, physical inactivity, hypertension, hypercholesterolemia, abuse of alcohol and psychoactive substances are indicators for the development of chronic noninfectious diseases. According to the ratings set presented in the Development healthcare plan, infectious diseases were not found to be a leading health problem in Serbia [4].

\section{Health promotion and prevention programs}

The application of national programs of health promotion in Serbia has changed the perception of health and illness, so that the attention of social community is more directed towards life-style and health risk factors. Raising the awareness of health as a personal responsibility, as well as responsibility of the society is identified as the major task, and is based on the association of risk factors with social and physical living conditions [7].

In this sense, the illustrative example of successful preventive program is a significant decrease in smoking and the formation of preventive healthcare centers for adults in primary healthcare sector

In order to address major health problems, the issue of preventive healthcare programs at the national level that include both health services and community have been started. They include the following programs:

- The strategy for prevention and control of chronic no communicable diseases in Serbia

- The national program to prevent cervical cancer in Serbia

- The national program of cardiac health

- The national program for breast cancer prevention in Serbia

- The national program for colon cancer tumor prevention in Serbia

- The national program of early detection of Diabetes type 2 in Serbia, the development mental healthcare strategy

- The national strategy to fight a HIV / AIDS

- Strategy for the fight against drugs

- Public Health Strategy

- Strategy of youth health [3].

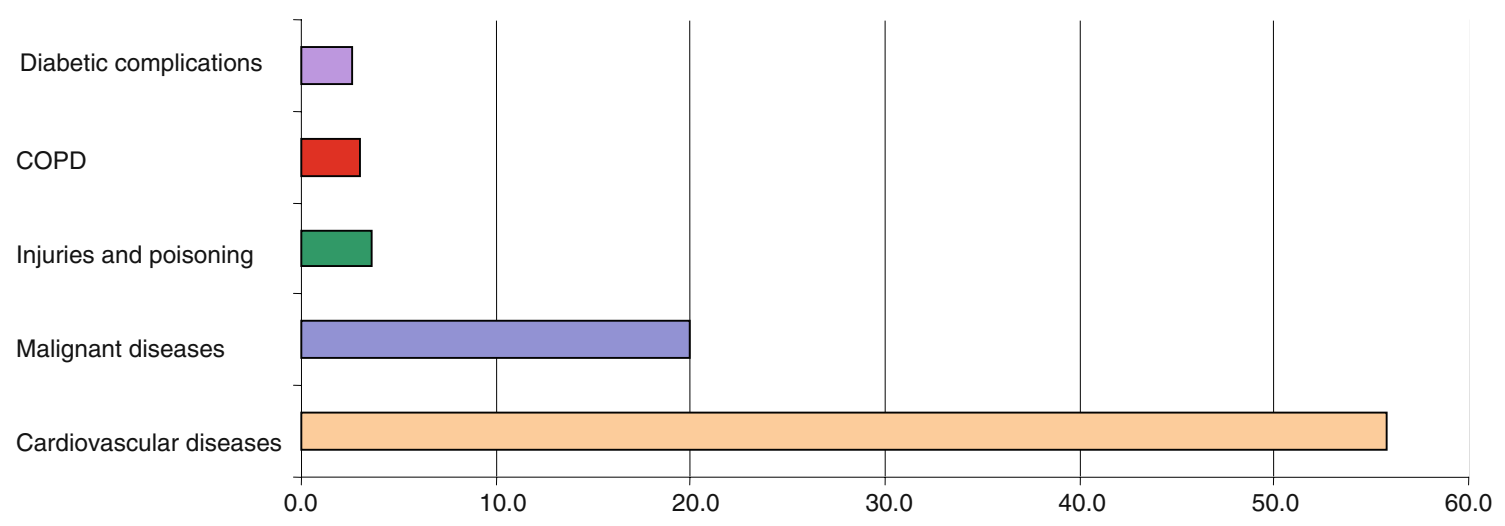

Fig. 4 Percentage of certain diseases in the structure of mortality in Serbia 
Fig. 5 Structure of employees in the health service in Serbia

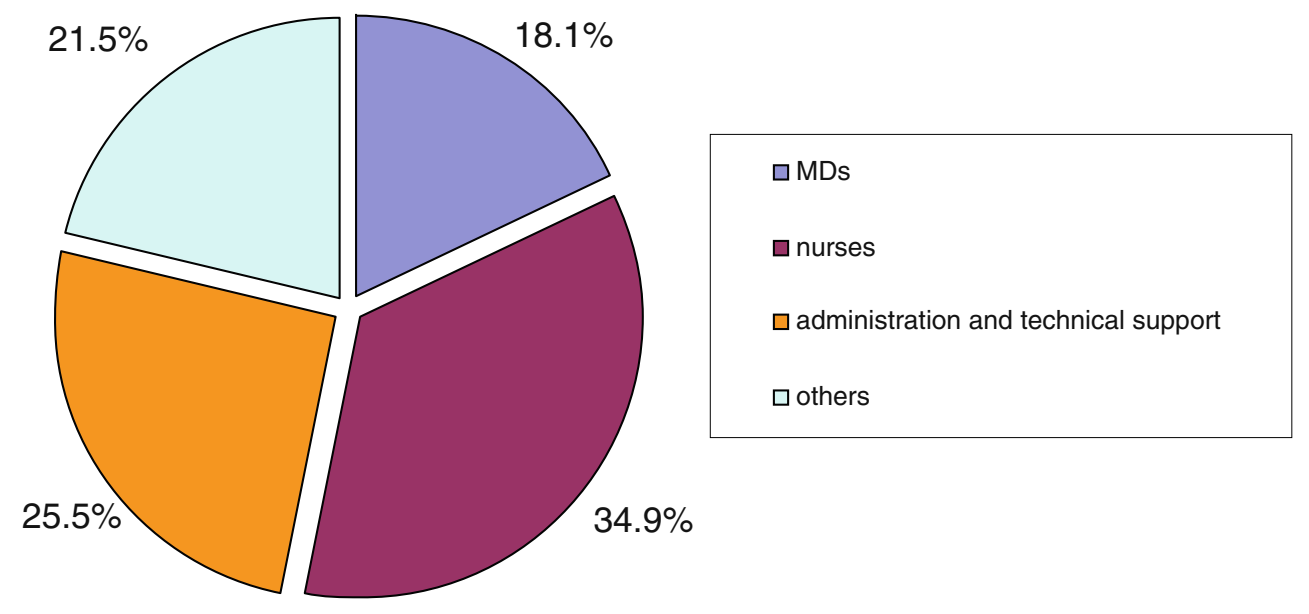

\section{Health service capacity}

Hospital facilities in Serbia comprise of 38590 beds, providing 525 beds per 100000 inhabitants, which is slightly lower than the EU average ( 570 beds per 100000 inhabitants).

In 2008, the total number of employees was 114317 , and the employment structure included: $18.1 \%$ medical doctors (MDs) (74.3\% of specialists), 34.9\% nurses, $25.5 \%$ administrative and technical staff and $21.5 \%$ other health workers (Fig. 5).

Medical doctors employed in the governmental institutions are represented as 281 physicians per 100000 inhabitants and this number is lower in comparison with EU countries (321 physicians per 100000 inhabitants). On the other hand, according to the Serbian Medical Chamber, the number of licensed physicians is 28413 , which gives a number 387 MDs per 100000 inhabitants. The number of nurses/medical technicians employed in governmental health institutions is 572 , which is lower in comparison to EU countries where the number is 745 per 100000 inhabitants. According to the Chamber of nurses, the number of licensed nurses is substantially higher: 721 nurses per 100000 inhabitants [4].

At the beginning of 2009 , within the private health sector, 5,000 health institutions comprised of seven health centers, 72 hospitals, 136 policlinics, 2,000 medical offices, 1,400 pharmacies and 200 different laboratory and diagnostic clinics. Although the private practice is well developed, public and private sectors still have clear boundaries [1].

One of the evident problems of Serbian healthcare system is unequal territorial distribution of medical staff, as well as a high number of unemployed doctors. In 2008, 1,750 medical doctors, 1,145 doctors of dentistry and 207 graduate pharmacists were on the unemployment list.

\section{The use of healthcare facilities}

In 2008, the number of registered hospitalizations was 1106 643 , with the hospitalization rate of 15.1 per 100 inhabitants that is lower in comparison with average value in the Europe (19.2) and in e EU countries (17.9). The average length of
Fig. 6 Use of healthcare in Serbia and the European Union in 2008

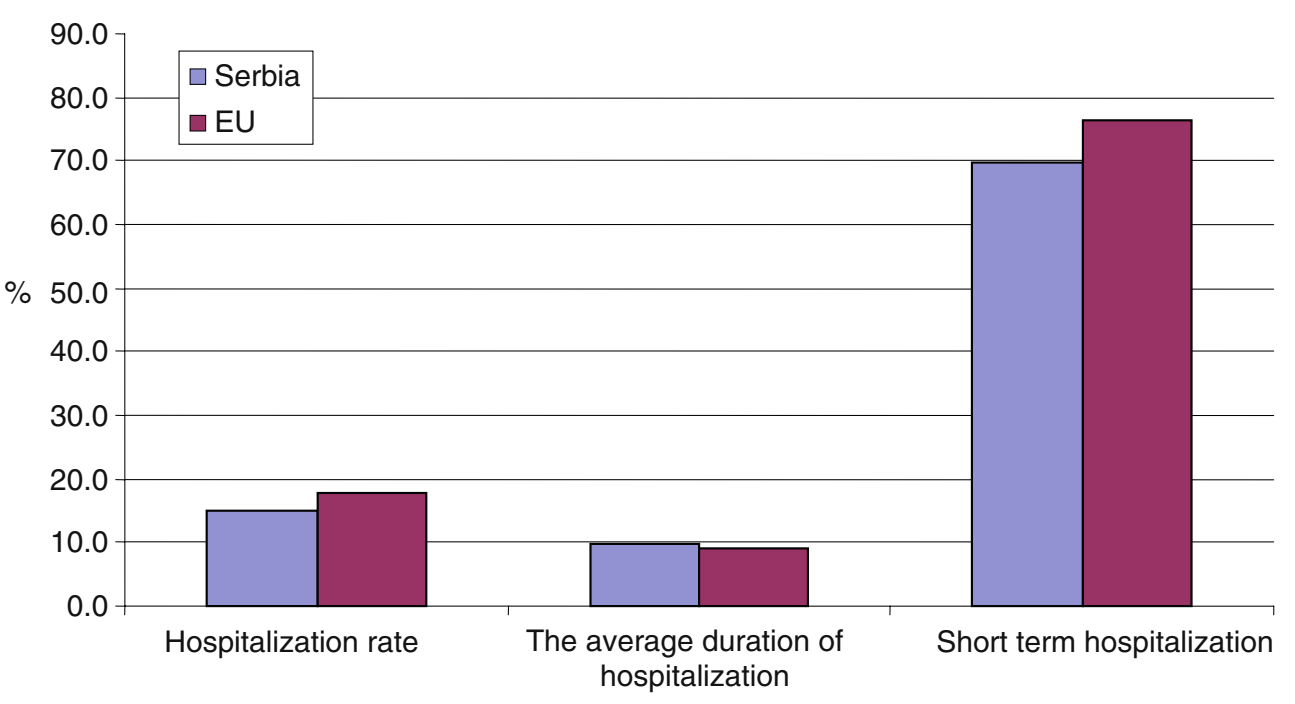


treatment was 9.7 days that is almost at the level of the EU (9 days). Lower average daily bed occupancy of short-term hospitalization (69.8\%) compared to the EU average (76.3\%) is probably more a result of poor adjustment of bed distribution and current needs, due to existing models of funding, than of real excess of beds (Fig. 6).

\section{Healthcare financing}

The healthcare in Serbia is dominantly ( $>90 \%)$ financed from the contributions of the compulsory health insurance. The rest is financed from the budget relocated to the uninsured persons exposed to increased risk of disease such as uninsured subjects, refugees and displaced persons. Financing of healthcare institutions is accomplished through the contracts, based on the purchase of the work plan that includes the type and number of health services and the number and structure of employees. Healthcare is funded by payments of salaries of employees (56.3\%), cost of energy, medicines, hospital and medical materials, etc. (22.8\%), medicines issued on prescription (12.1\%), compensation for sick leave (3.9\%) and compensation for support medical devices (1\%).

The long lasting preparations for financing of primary healthcare sector, following the capitation model, have been completed. By applying this model, positive changes in terms of control of spending funds, improved responsibility of MDs and better quality of primary healthcare are expected.

Announcement of the funding application model based on-Diagnosis Related Groups (DRG), and episodes of treatment of patients with similar clinical characteristics and payment services group, regardless of the available capacity, demands significant changes of the existing financing. This particularly implies in changes in the management of hospital facilities and their resources, in particular human resources.

\section{Project "Development of Health of Serbia - additional funding"}

Ministry of Health carried out health project "Development of Serbia - additional funding" in accordance with the Loan Agreement between the Republic of Serbia and the International Bank for Reconstruction and Development. It is guided by the goal to support capacity building in order to develop sustainable healthcare system aimed at results, in which providers of health services rewards for quality and efficiency and where health insurance provides access to affordable and effective healthcare [3]. The project has three components: (1) information technology, (2) management of hospitals and improving the quality and (3) monitoring, evaluation and communication within the Ministry of Health.
Within the frame of project, each health institution is obliged to:

- Implement the process of accreditation with the Accreditation Agency

- Provide conditions for the implementation of information technology

- Introduce regular clinical paths as a standard procedure

- Develop, in collaboration with the Ministry of Health, the plan of quality improvement, as the basis for future investments.

The project, which started in 2009 , is expected to be completed in 2011. It is already in advanced stage and includes all healthcare facilities in Serbia.

\section{Conclusion}

Unfavorable demographic situation and especially the deterioration of the socioeconomic situation caused by the global economic crisis had a negative impact on the healthcare system in Serbia. New reform actions have contributed to the positive changes in developing the capacity of health services, use of healthcare, health promotion, and implementation of preventative programs. The improvement of the health at the population level is significant in relation to the total transition environment, but still below the expected and satisfactory value. The changes in the financing of the health services that are expected, presently do not integrate the private sector. The implementation of the Project Development of Health of Serbia-additional funding will raise the level of sustainability of the healthcare system in Serbia in which service providers will be rewarded for the results measured by the level of quality and efficiency of the provided healthcare.

\section{References}

1. Knezevic T. Health of population of Serbia-analytical study 1997-2007. Belgrade: Institute of Public Health of Serbia; 2008.

2. Government of the Republic of Serbia, documents available at: http://www.srbija.gov.rs/news/documents.

3. Ministry of Health of the Republic of Serbia, documents available at: http://www.zdravlje.gov.rs.

4. Knezevic T. Pracenje pokazatelja kvaliteta zdravstvene zastite. Belgrade: Institute of Public Health of Serbia; 2009.

5. Bajec J, Krstic D, Pejin-Stokic L, Penev G. Social Protection and social inclusion in the Republic of Serbia. Belgrade: Economics Institute of Serbia; 2008.

6. European Health for all Database (HFA-DB), document available at http://www.euro.who.int/hfadb

7. Bilthoven. Care for health. In: PHSF-2006. RIVM 2006. http:// www.rivm.nl/vtv/phsf2006, Assessed 29th May 2007. 